\title{
Perinatal Rat Lung Retinol (Vitamin A) and Retinyl Palmitate
}

\author{
RICHARD D. ZACHMAN, BHARATI KAKKAD, AND FRANK CHYTIL \\ Perinatal Center, University of Wisconsin, Madison, Wisconsin 53715 [R.D.Z.] and Department of Biochemistry, \\ Vanderbilt University School of Medicine, Nashville, Tennessee 37240 [B.K., F.C.]
}

\begin{abstract}
The potential role for retinol (vitamin A alcohol) in the differentiation of the developing lung prompted this study in the perinatal rat. High performance liquid chromatography was used to separate, detect, and quantitate retinol and retinyl palmitate in lipid extracts of tissue and serum. Fetal and maternal blood showed the presence of retinol, whereas no retinyl palmitate was detected. On the other hand, fetal and postnatal lungs contained retinyl palmitate as well as retinol. Considerable changes in the content of lung retinyl palmitate were found during lung development. Fetal lungs (17-21 days of gestation) contained $2.3 \pm 0.36 \mu \mathrm{g} / \mathrm{g}$ wet weight (mean \pm SD) of retinyl palmitate and $0.14 \pm 0.05 \mu \mathrm{g} / \mathrm{g}$ of retinol. Lungs of pups (1-10 days old) contained much less retinyl palmitate, $0.63 \pm 0.20 \mu \mathrm{g} / \mathrm{g}$, whereas the amount of retinol was the same as in fetal lungs. The surprisingly high content of retinyl palmitate in fetal lung and its depletion after birth may be functionally related to retinol action in the developing lung. (Pediatr Res 18:1297-1299, 1984)
\end{abstract}

\section{Abbreviation}

HPLC, high performance liquid chromatography

Retinol (vitamin A) in lung was demonstrated over 50 years (15) ago, but the exact function of this nutrient in pulmonary metabolism and its potential relationship to neonatal lung development is only of recent interest.

Retinol is essential for differentiation and integrity of respiratory epithelial cells of upper airways $(1,25)$. Lung cytosol contains intracellular retinol and retinoic acid-binding proteins (17, 18); the quantity of the latter changes postnatally in the rat (17). Since one-fourth of the cells in the alveolar region of lung are epithelial (6), clinical studies on nieonatal retinol status $(3,13$, $19,21)$ and retinol's possible relationship to neonatal lung disease $(10,20)$ are being assessed.

The ability of rat lung to accumulate retinol after large doses (15) poses questions concerning the existence of a lung storage form of vitamin A, its chemical character, and function. Adult rat lungs contained retinyl esters after intravenous injections of chylomicra labeled with radioactive retinyl esters. The major ester was retinyl palmitate (9). Recently, HPLC identified retinyl palmitate and smaller amounts of other retinyl esters in adult rat lung (2). Although it is well established that retinyl esters (mainly

Received January 2, 1984; accepted June 5, 1984.

Correspondence may be addressed to Dr. Richard D. Zachman, University Wisconsin Perinatal Center, 202 S. Park Street, Madison WI 53715.

This work was supported in part by National Institutes of Health Grants HL27358. HL-14214. HL-15341, and HD-09195. palmitate) are storage forms of retinol in the liver which are depleted during vitamin A deficiency (for review, see Ref. 8), no information is available thus far about the presence and possible function of retinyl palmitate in the fetal lung.

The objective here was to study whether fetal lungs contain retinyl palmitate and to determine whether the amounts of retinol and retinyl palmitate change during perinatal development of rat lung.

\section{MATERIALS AND METHODS}

Chemicals. High purity spectral grade solvents of Burdick and Jackson Laboratories, Inc. (Muskegan, MI) were used. Synthetic all-trans-retinol, retinyl acetate, and retinyl palmitate were from Sigma Chemical Co. (St. Louis, MO).

High performance liquid chromatography. Retinol and retinyl palmitate were determined by HPLC using a programmable liquid chromatographic system (Spectra Physics; San Jose, CA). The UV spectrophotometer system was a ISCO-V ${ }^{4}$ variable detector (Lincoln, NE). The HPLC column was reversed-phase $\mu$ Bondapak $\mathrm{C}_{18}(10-\mu \mathrm{m}$ particle size) stainless steel column, 3.9 $\mathrm{mm}$ i.d. $\times 30 \mathrm{~cm}$ (Waters Associates, Inc., Milford, MA). A modification of the system previously described was used (2). In our system, $100 \%$ methanol was used as the mobile phase to separate retinol, retinol acetate (added to some extracts as an internal standard), and retinyl palmitate. The flow rate was adjusted so retinol was eluted in the 5 th min and retinyl palmitate in the 11 th $\mathrm{min}$. The flow rates were as follows: $0-5 \mathrm{~min}, 1.0$ $\mathrm{ml} / \mathrm{min} ; 6 \mathrm{~min}, 1.5 \mathrm{ml} / \mathrm{min} ; 7 \mathrm{~min}, 2.0 \mathrm{ml} / \mathrm{min} ; 12 \mathrm{~min}, 1.5$ $\mathrm{ml} / \mathrm{min}$; and $13 \mathrm{~min}$, back to $1.0 \mathrm{ml} / \mathrm{min}$.

Standard curves of peak heights at identical sensitivities of the instrument against known amounts of retinol and retinyl palmitate were used. The standard solutions of retinol and retinyl palmitate were prepared in $100 \%$ ethanol and quantitated using the extinction coefficient of $E_{1 \mathrm{~cm}}^{1 \%}$ for retinol of 1780 at $325 \mathrm{~nm}$ and for retinyl palmitate of 940 at $325 \mathrm{~nm}(5,12)$.

Tissue source and extraction method. Disease-free pregnant albino rats were obtained from SASCO (St. Louis, MO). At various times, pregnant mothers were anesthetized with ether and individual fetuses were removed for dissection. The live fetuses were quickly decapitated, and the lungs were removed, placed on dry ice, and analyzed within 30-60 min.

Postnatal lungs were obtained by decapitation, quick dissection, and placing on dry ice. Occasional hemorrhagic lungs, which were obvious from their appearance and increased weight, were not used. While still alive under anesthesia, some maternal rats received a tracheostomy and were then placed on a rodent respirator (Model 680, Harvard Apparatus Co., Millis, MA). The chest cavity was then opened, the pulmonary artery was catheterized, and the lung was perfused with $10-12 \mathrm{ml}$ of warm saline simultaneously with ventilation over a 2 -min period. This resulted in white, virtually blood-free adult lungs. 
Tissue was processed according to established methods for lipid extraction (7). The samples (approximately $100 \mathrm{mg}$ wet weight) were homogenized by Polytron P-10 (Kinematika, Switzerland) for $1 \mathrm{~min}$ with 20 volumes of a mixture of $\mathrm{CHCl}_{3}: \mathrm{CH}_{3} \mathrm{OH}, 2: 1$, containing $50 \mu \mathrm{g} / \mathrm{ml}$ of butylated hydroxytoluene, and then filtered. One $\mathrm{ml}$ of the filtrate was added to $0.2 \mathrm{ml}$ of $0.37 \% \mathrm{KCl}$, mixed, and then centrifuged to separate the layers. The top layer was removed. The bottom layer was evaporated under nitrogen. The residue was dissolved in $25 \mu \mathrm{l}$ $\mathrm{CHCl}_{3}$ and $25 \mu \mathrm{l} \mathrm{MeOH}$, and an aliquot of not more than $25 \mu \mathrm{l}$ was injected onto the HPLC column. The sample was protected from direct light by covering iced containers with aluminum foil. A typical HPLC chromatogram of retinol, retinyl acetate, and retinyl palmitate shows clear separation of standards (Fig. $1 A$ ). Serum was mixed with an equal volume $100 \%$ ethanol and extracted twice with 4 volumes of HPLC-grade hexane.

DNA determination of two to four lung homogenates at four different perinatal ages (in duplicate) was done by the diphenylamine method (4).

\section{RESULTS}

First, we have established that fetal lung contains, in addition to retinol, a considerable amount of material which eluted from the HPLC in the position of retinyl palmitate (Fig. 1B). No retinyl palmitate was detected in samples of fetal or maternal sera.

The amount of retinol and retinyl palmitate in extracts of lungs of rats of various perinatal ages was then determined. The pattern of retinol and retinyl palmitate content in prenatal and postnatal lung is shown in Figure 2. There was no apparent change in retinol content in lung from 17-day-old fetuses to 10 days after birth. The mean value was $0.14 \pm 0.05 \mu \mathrm{g} / \mathrm{g}$ wet weight for 24 fetal lungs and $0.11 \pm 0.02 \mu \mathrm{g} / \mathrm{g}$ for 17 neonatal lungs. The data points from three litters at 17-day gestation are only suggestive that the amount of retinol was lower $(0.09 \mu \mathrm{g} / \mathrm{g})$. The amount of lung retinyl palmitate changes abruptly after birth. In the 24 fetal lung samples of 17-20.5 days gestation, the mean

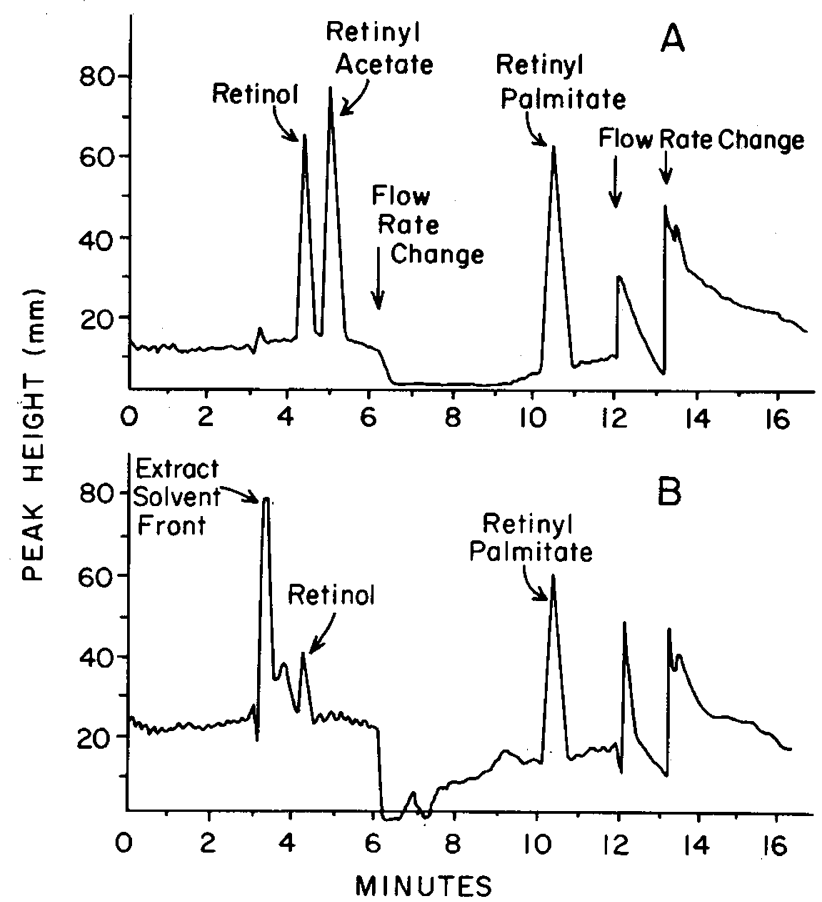

Fig. 1. HPLC chromatograms $A$, separation of standards used for the determination of rat lung retinol and retinyl palmitate (retinyl acetate was added as an external standard). $B$, separation of retinol and retinyl palmitate in a fetal lung extract prepared as described in "Materials and Methods."
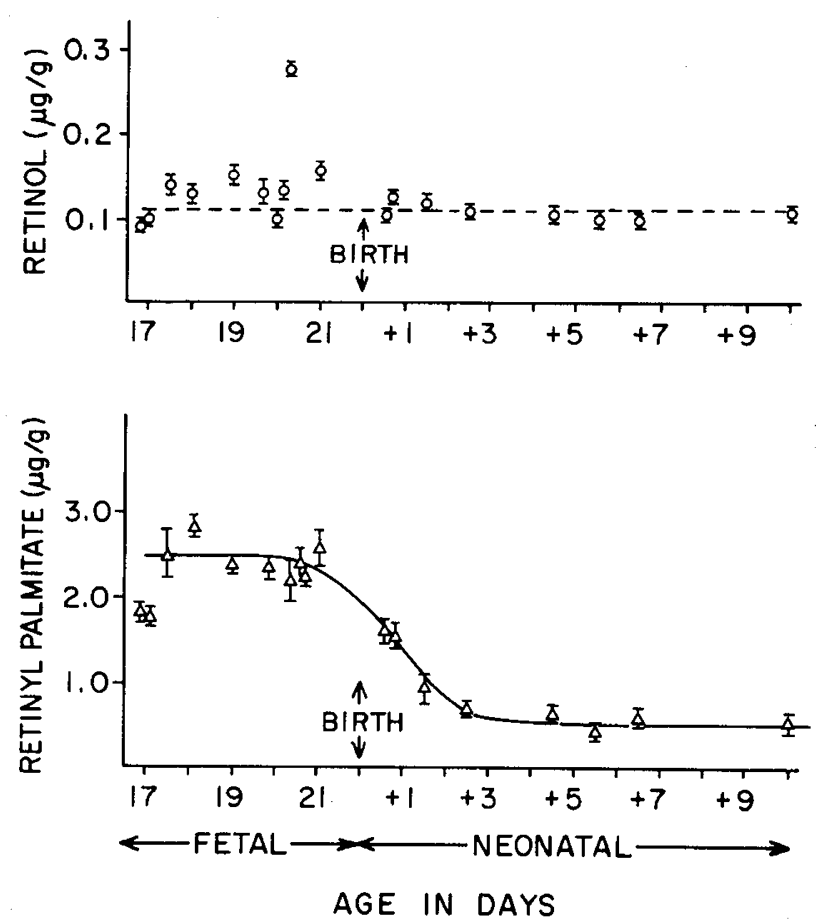

Fig. 2. Retinol and retinyl palmitate in developing lung. A total of 11 fetal (two of three 17-day values are identical) and eight postnatal litters were analyzed. The points show mean \pm SD of three separate littermates. After 20 days gestation and postnatally, only one lung was needed from each fetus. At 18-20 days, 1.5-3 lungs were pooled. At 17 days gestation, 7-9 fetal lungs of the same litter were required, and the point is a mean of two separate determinations.

Table 1. Lung retinol and retinyl palmitate content based on lung DNA

\begin{tabular}{cccc}
\hline Day & Retinol & & $\begin{array}{c}\text { Retinyl } \\
\text { palmitate }\end{array}$ \\
\hline Fetal & & $(\mu \mathrm{g} / \mathrm{mg} \text { DNA })^{*}$ & \\
$18-19$ & 0.06 & & 1.0 \\
20 & 0.07 & & 1.2 \\
Postnatal & & & 0.29 \\
$1.5-4$ & 0.06 & & 0.35 \\
10 & 0.07 & \\
\hline
\end{tabular}

* Mean values of 1 litter at each age.

was $2.3 \pm 0.36 \mu \mathrm{g} / \mathrm{g}$ in comparison to $0.63 \pm 0.20 \mu \mathrm{g} / \mathrm{g}$ in 17 lungs 1.5-10 days after birth $(p<0.001)$. This difference in retinyl palmitate content is as striking when calculated per $\mathrm{mg}$ lung DNA (Table 1).

\section{DISCUSSION}

Since this is the first report on the presence of retinyl palmitate in fetal lung, the quantitation by HPLC used here must be compared with data on adult lungs. Our method used on bloodfree adult rat lung gave retinyl palmitate $(2.5-4.0 \mu \mathrm{g} / \mathrm{g})$ values that compare favorably with those reported earlier for total lung retinol $(1.5 \mu \mathrm{g})(15)$ and the recent report $(8 \mu \mathrm{g} / \mathrm{g})$ using HPLC (2). Our interest was only in perinatal retinyl palmitate. Therefore, longer retention times were not used that would assay retinyl stearate, an ester that accounts for about one-quarter of adult rat lung retinyl ester $(2,9)$. The HPLC method used here was clearly reproducible. Analysis of four separate lungs from the same litter or analysis of six lungs from two separate but identical gestation litters on the same day gave a standard deviation of within 12$14 \%$ of the mean. Finally, analysis of fetal livers using this method showed retinyl palmitate at 17 days gestation of $6.5 \mu \mathrm{g} /$ 
$\mathrm{g}$, at 20 days gestation it was $11 \mu \mathrm{g} / \mathrm{g}$, and in liver of 1.5-day old pups it was $24 \mu \mathrm{g} / \mathrm{g}$. Over $95 \%$ of the total liver retinol extracted was present as retinyl palmitate. These values are in close agreement with the recent values of Ismadi and Olson (11) on total retinol in the livers of the 20 -day rat fetus of $5-7 \mu \mathrm{g} / \mathrm{g}$, and the suckling 1.5 -day rat pup of $20 \mu \mathrm{g} / \mathrm{g}$.

Our results show that fetal rat lung contains 15-20 times more retinyl palmitate than free retinol, but the ratio abruptly falls to only 6-8 times as much 1-10 days after birth (Fig. 2). Although the water content of lung would obviously be different in the fetal and postnatal lung, the marked differences in perinatal lung retinyl palmitate in comparison to retinol are additionally documented when based on lung DNA at four separate perinatal ages (Table 1). There are at least two possibilities to explain the presence of such high fetal lung retinyl palmitate and its rapid decrease at birth. Firstly, this could represent general nonspecific storage of retinyl ester derived in some form from the maternal circulation. That source would end with birth. In the presence of limited reserves of retinol, a greater portion of the total body retinol (as retinyl ester) is found in kidney and possibly other organs with lesser amounts in liver (14), and it is probable that limited reserves are present in both fetal mice and rats (16). Little placental transfer of maternal blood retinyl palmitate should occur since the major form of the vitamin in maternal plasma is retinol bound to retinol-binding protein (22). Indeed, we could not detect retinyl palmitate in fetal blood, maternal blood, or in placenta (data not shown). If there were placental esterification of retinol and rapid release of retinyl palmitate, this ester should be detected in fetal blood. This appears not to be the case since we could not demonstrate retinyl palmitate in fetal blood. There also would be no retinyl palmitate expected in fetal blood due to the absence of a postprandial absorptive state in the fetus itself. Although retinol has been noted in human amniotic fluid, no esters were found (24). All these observations suggest that fetal lung esterifies retinol.

A second reason to explain the high fetal lung retinyl palmitate stores is that they are functionally competent. Whether the fetal liver has the ability to release retinol into the blood stream to make it available for other vitamin A-dependent organs is not known. The possibility of a certain autonomy of the lungs which is not dependent on the supply of liver retinol is an attractive but yet unsolved one. If such were the fact, the fetal lung has apparently sufficient local vitamin A stores necessary for providing and maintaining essential lung epithelial differentiation and integrity during the perinatal period in which the alveoli are formed (23). The change in lung retinyl palmitate is remarkably different than what occurs in liver. We have observed that as perinatal age changed from the 17-day fetus to the 1.5-day-old neonate, the lung retinyl palmitate decreased 4-fold (2.3 to 0.6 $\mu \mathrm{g} / \mathrm{g}$ ), but the liver retinyl palmitate increased 4-fold (6.5 to 24 $\mu \mathrm{g} / \mathrm{g})$. Other reports confirm this rapid rise in perinatal rat liver retinyl esters (11). The rapid decrease in lung retinyl palmitate at birth is also interesting in that it coincides with the postnatal rise in lung cellular retinoic acid-binding protein (17). Meanwhile, there was an obvious steady level of perinatal lung retinol (Fig. 2), paralleling unchanging levels of cellular retinol-binding protein pre- and postnatally (17). Hydrolysis of stored retinyl palmitate to retinol and further oxidation to metabolically active retinoic acid could be important during the perinatal period.

The detection of retinyl palmitate in fetal lungs reported here poses the question of the functional role of the retinyl esters in lungs. Until now, liver has been emphasized as being the primary source of retinol for the retinol-dependent organs (8). A great deal is known about retinol metabolism in vitamin A deficiency, but several questions remain unanswered, including how retinol stores are mobilized in normal vitamin A-sufficient animals. The presence of a considerable amount of fetal lung retinyl palmitate and its depletion during perinatal development suggests that these stores are physiologically functional and the utilization of these stores in lung development might be independent of liver vitamin $\mathrm{A}$.

Acknowledgment. The authors wish to thank David Ong for help with the HPLC method.

\section{REFERENCES}

1. Anzano MA, Olson JA, Lamb AJ 1980 Morphologic alterations in the trachea and the salivary gland following the induction of rapid synchronous vitamin A deficiency in rats. Am $\mathrm{J}$ Pathol 98:717-732

2. Bhat PV, Lacroix A 1983 Separation and estimation of retinyl fatty acyl esters in tissues of normal rat by high-performance liquid chromatography. J Chromatogr 272:269-278

3. Brandt RB, Mueller DG, Schroeder JR, Guyer KE, Kirkpatrick BV, Hutcher NE, Ehrlich FE 1978 Serum vitamin A in premature and term neonates. J Pediatr 92:101-104

4. Burton K 1956 A study of the conditions and mechanism of the diphenylamine reaction for the colorimetric estimation of deoxyribonucleic acid. Biochem J 62:315-323

5. Catignani GT, Bieri JG 1983 Simultaneous determination of retinol and $\alpha$ tocopherol in serum or plasma by liquid chromatography. Clin Chem 29:708-712

6. Crapo JD, Barry BE, Gehr P, Backofen M, Weibel ER 1982 Cell number and cell characteristics of the normal human lung. Am Rev Respir Dis 125:740745

7. Folch J, Lees M, Sloane-Stanley GH 1957 Simple method for the isolation and purification of total lipids from animal tissues. J Biol Chem 226:497-507

8. Goodman DS 1980 Vitamin A metabolism. Fed Proc 39:2716-2722

9. Goodman DS, Huang HS, Shiratori T 1965 Tissue distribution and metabolism of newly absorbed vitamin A in the rat. J Lipid Res 6:390-396

10. Hustead GA, Gutcher GR, Anderson SA, Zachman RD 1984 Relationship of vitamin A (retinol) status to lung disease in the preterm infant. J Pediatr 105:610

11. Ismadi SD, Olson JA 1982 Dynamics of the fetal distribution and transfer of vitamin $A$ between rat fetuses and their mother. Int $J$ Vitam Nutr Res 52:111-118

12. Ito $\mathrm{YL}$, Zile M, Ahrens M, DeLuca $\mathbf{H} 1974$ Liquid-gel partition chromatography of vitamin A compounds: formation of retinoic acid from retinyl acetate in vivo. J Lipid Res 15:517-524

13. Montreewasuwat N, Olson JA 1979 Serum and liver concentrations of vitamin $A$ in Thai fetuses as a function of gestational age. Am J Clin Nutr 32:601606

14. Moore T 1957 Vitamin A. Elsevier Publishing Company, Amsterdam p 508

15. Moore T 1957 Vitamin A. Elsevier Publishing Company, Amsterdam, pp 208210

16. Moore T 1971 Vitamin A transfer from mother to offspring in mice and rats. Int J Vitam Nutr Res 41:301-306

17. Ong DE, Chytil F 1976 Changes in levels of cellular retinol and retinoic acidbinding proteins of liver and lung during perinatal development of rat. Proc Natl Acad Sci USA 73:3976-3978

18. Ong DE, Crow JA, Chytil F 1982 Radioimmunochemical determination of cellular retinol- and cellular retinoic acid-binding proteins in cytosols of rat tissues. J Biol Chem 257:13385-13389

19. Shenai JP, Chytil F, Jhaveri A, Stahlman MT 1981 Plasma vitamin A and retinol-binding protein in premature and term neonates. J Pediatr 99:302305

20. Shenai JP, Chytil F, Stahlman MT 1982 Vitamin A status of neonates with chronic lung disease Pediatr Res 16:177A (abstr)

21. Shenai JP, Chytil F, Stahlman MT 1982 Liver vitamin A reserves of very low birthweight (VLBW) neonates. Pediatr Res 16:177A (abstr)

22. Takahashi YI, Smith JE, Goodman DeWS 1977 Vitamin A and retinol-binding protein metabolism during fetal development in the rat. Am J Physiol 233:E263-E272

23. Thurlbeck WM 1975 Postnatal growth and development of the lung. Am Rev Respir Dis 111:803-844

24. Wallingford JC, Milunsky A, Underwood BA 1983 Vitamin A and retinolbinding protein in amniotic fluid. Am J Clin Nutr 38:377-381

25. Wolbach SB, Howe PR 1925 Tissue changes following deprivation of fat soluble A vitamin. J Exp Med 42:753-777 